\title{
Proliferação celular nos linfomas caninos
}

Sara Maria de Carvalho e SUZANO ${ }^{1}$

Julio Lopes SEQUEIRA²

Adriana Wanderley de Pinho

PESSOA $^{3}$

Camila Dias PORTO ${ }^{1}$

Deílson Elgui de OLIVEIRA ${ }^{4}$

Correspondência para:

Sara Maria de Canvalhoe Suzano-Rua Dois de Dezembro, 72 ap. 805 Flamengo, Rio de Janeiro - RJ CEP 22220-040

Recebido para publicação: 30/03/2007 Aprovado para publicação: 31/01/2008

\author{
1 - Curso de Pós-Graduação em Medicina Veterinária, Área de Patologia \\ Veterinária da Faculdade de Medicina Veterinária e Zootecnia da Universidade \\ Estadual Paulista, Botucatu-SP \\ 2 - Departamento de Clínica Veterinária da Faculdade de Medicina Veterinária e \\ Zootecnia da Universidade Estadual Paulista, Botucatu-SP \\ 3 - Curso de Medicina Veterinária da Universidade Estadual do Ceará, Fortaleza- \\ $\mathrm{CE}$ \\ 4 - Departamento de Patologia da Faculdade de Medicina da Universidade \\ Estadual Paulista, Botucatu-SP
}

\section{Resumo}

Palavras-chaves:

Linfoma.

O estudo dos linfomas caninos além de abordar a classificação morfológica e imunofenotípica necessita ser ampliado para que se tenha a avaliação da cinética celular. Esta verificação só pode ser feita com segurança quando são avaliados os parâmetros que indicam a taxa de proliferação celular. No homem, estes fatores têm influência no prognóstico e no tratamento dos limfomas. Os 40 linfomas utilizados neste trabalho foram classificados de acordo com a classificação de Kiel e a imunofenotipagem utilizou CD3 (linfócitos T) e CD79a (linfócitos B). A proliferação celular foi avaliada pelos métodos de contagem dos AgNORs e Ki-67 (MIB-1) De acordo com a classificação de Kiel os linfomas de alto grau foram os mais freqüentes, a imunofenotipagem mostrou a mesma freqüência de linfomas T e B. Quando avaliada a proliferação celular houve diferença significativa entre os linfomas de alto e baixo grau tanto pelo método do AgNOR como do KI-67.(MIB-1), porém não foram estatisticamente entre os imunofenótipos Entre as neoplasias de alto grau de malignidade a média de número de NORs por núcleo de célula neoplásica foi de 1,37 \pm 0,32, e nos casos de baixo grau de 0,98 \pm 0,36, de acordo com o KI-67 a média do percentual de células positivas foi de $43,19 \% \pm 19,01$, e $14,09 \% \pm 11,74$ nos casos de alto e baixo grau, respectivamente.

\section{Introdução}

Os linfomas estão entre as neoplasias mais freqüentes na espécie canina ${ }^{1,2,3,4}$, e em estudos recentes pode-se observar a necessidade de avaliar, além da classificação morfológica e o imunofenótipo, o índice de proliferação celular ${ }^{5}$.

A proliferação celular relacionada com as neoplasias tem sido amplamente estudada por mostrar boa correlação com o comportamento biológico destes tumores além de a adicionar informações que orientam o tratamento e o prognóstico. ${ }^{6}$ Há muitos métodos para a avaliação da proliferação celular, entre estes estão as técnicas histoquímicas para a contagem dos AgNORs (Argyrophil Nucleolar Organizer Regions) ou ainda a avaliação imunoistoquímica, utilizando-se a marcação do antígeno Ki-67 (MIB-1).

Os AgNORs são estruturas intranucleares, relacionadas com a síntese de proteínas nas células em proliferação. $\mathrm{O}$ grande número de AgNORs reflete um alto índice de proliferação. Esses parâmetros têm sido utilizados com grande eficácia nos linfomas do homem e do cão. As neoplasias de grau alto de malignidade possuem um número maior de AgNORs e estes apresentam-se distribuídos difusamente no núcleo enquanto os tumores de grau baixo 
de malignidade possuem AgNORs agregados dentro dos nucléolos. ${ }^{7}$

Métodos imunoistoquímicos têm sido empregados para a detecção de proteínas associadas à proliferação celular tanto nas neoplasias humanas como na Medicina Veterinária. ${ }^{6,8} \mathrm{O}$ principal marcador das células em proliferação é o antígeno Ki-67 (MIB-1). ${ }^{5,9}$

O antígeno Ki-67 (MIB-1) pode ser detectado em todas as fases do ciclo celular menos na fase $G_{0} \cdot{ }^{10}$ Este tem relação direta com a fração de crescimento de uma população celular e é considerado, atualmente, como o melhor marcador imunoistoquímico de proliferação celular. ${ }^{8}$ Esta determinação tem valor prognóstico nos linfomas não-Hodgkin humanos, pois a análise desse índice pode estabelecer um fator independente para cada caso. ${ }^{11}$

$\mathrm{Na}$ espécie canina, a quantificação do antígeno Ki-67 (MIB-1) nos diferentes grupos de linfomas, pode resultar em aumento na acurácia das classificações dos linfomas caninos. Alguns autores observaram uma correlação positiva entre a proporção de células positivamente marcadas pelo Ki-67, a morfologia celular, o imunofenótipo e o grau de malignidade das neoplasias. ${ }^{12}$

\section{Material e Método}

Foram utilizados 40 casos de linfomas caninos, fixados em formalina $10 \%$ e submetidos ao processamento histológico de rotina, corados pelo método da Hematoxilina e Eosina (HE) e classificados de acordo com a classificação morfológica de Kiel. Para a determinação do imunofenótipo, foram empregados marcadores linfóides para linfócitos T, o anticorpo policlonal anti-CD3 (Dako) na diluição de 1:100 e para linfócitos $\mathrm{B}$, o anticorpo monoclonal anti-CD79a (Dako) na diluição de 1:50.

A avaliação quantitativa de AgNORs foi realizada por meio da contagem direta dos pontos de AgNORs presentes nos núcleos de 100 células em cada caso analisado, em microscópio óptico na objetiva de imersão.

Foi utilizado para determinação do índice de proliferação celular o anticorpo anti Ki-67 clone MIB-1, monoclonal (DAKO) na concentração de 1:50, Todas as amostras passaram pela recuperação antigênica com solução tampão de citrato $10 \mathrm{mM}, \mathrm{pH}$ 6,0, em forno de microondas durante 15 minutos. O bloqueio da peroxidase endógena foi feito em solução de água oxigenada a 10 volumes por 15 minutos. Os anticorpos primários foram incubados durante 18 horas na tempreratura de $4{ }^{\circ} \mathrm{C}$. O sistema de detecção utilizado foi o kit EnVision Dual link (Dako). Para visualização da reação, as lâminas foram tratadas com solução de 3,3' diaminobenzidina (Liquid DAB - K3466 DakoCytomation) durante cinco minutos à temperatura ambiente. Os cortes foram contra-corados com hematoxilina de Harris, por 35 segundos.

Foi realizada a contagem de todas as células presentes em cinco campos aleatórios no aumento de $400 \mathrm{x}$ do microscópio óptico. Nestes mesmos campos aleatórios foram contadas as células positivas para cada anticorpo e estabelecida o percentual de células positivas. Posteriormente, os resultados foram submetidos ao teste $t$ (Student) a fim de verificar a diferença entre a média existente entre eles nos linfomas de alto e baixo grau de acordo com a classificação de Kiel (grau de significância $\mathrm{P}<0,05)$.

\section{Resultados}

Quando utilizada a classificação de Kiel ${ }^{13}$, foi observada a predominância dos linfomas de alto grau de malignidade, em 29 casos $(72,5 \%)$ seguidos por 11 casos de linfomas de baixo grau $(27,5 \%)$ (Tabela 1$)$.

No presente estudo obteve-se a mesma freqüência de linfomas $\mathrm{T}$ e linfomas B, ocorrendo em 17 casos (42,5\%), seguidos pelos Linfomas $\mathrm{T} / \mathrm{B}$ em seis casos $(15 \%)$. Os 13 casos de linfomas $T$ classificados como de grau alto de malignidade, foram classificados como imunoblásticos (Figura 1) e as neoplasias de grau baixo foram três casos 
Tabela 1 - Linfomas de acordo com a classificação de Kiel ${ }^{13}$

\begin{tabular}{lcc}
\hline \multicolumn{1}{c}{ Kiel } & $\mathbf{N}^{\mathbf{0}}$ de Casos & $\mathbf{\%}$ \\
\hline Imunoblástico & 19 & 47,5 \\
Centroblástico & 06 & 15,0 \\
Linfoblástico & 03 & 7,5 \\
Angioblástico & 01 & 2,5 \\
Centrocítico & 02 & 5,0 \\
Centrocítico-Centroblástico & 02 & 5,0 \\
Linfocítico & 02 & 5,0 \\
Linfoplasmacítico & 02 & 5,0 \\
Linfoma T pleomórfico & 03 & 7,5 \\
\hline TOTAL & 40 & 100 \\
\hline
\end{tabular}

de linfoma T pleomórfico e um linfocítico. Dentre os 17 casos de linfomas B, 11 casos foram de grau alto de malignidade e seis casos foram de grau baixo de malignidade, sendo cinco centroblásticos, quatro imunoblásticos, dois Linfoblásticos, dois centrocíticos-centroblasticos, dois centrocíticos, um linfocítico e um linfoplasmacítico

Dentre os 40 casos de linfomas, a contagem dos AgNORs foi realizada em 28 casos, sendo 21 de grau alto de malignidade (Figura 2) e sete casos de grau baixo de malignidade. Obteve-se uma média de número de pontos de NORs por núcleo de células neoplásicas. Entre as neoplasias de grau alto de malignidade a média foi de 1,37 $\pm 0,32$, e nos casos de baixo grau de $0,98 \pm$ 0,36 , e distribuição dos pontos foi dispersa pelo núcleo, correspondendo ao tipo II de padrão de distribuição. ${ }^{14}$ De acordo com Teste $\mathrm{t}$ (student) foi observada diferença estatisticamente significativa $(\mathrm{P}<0,05)$ entre

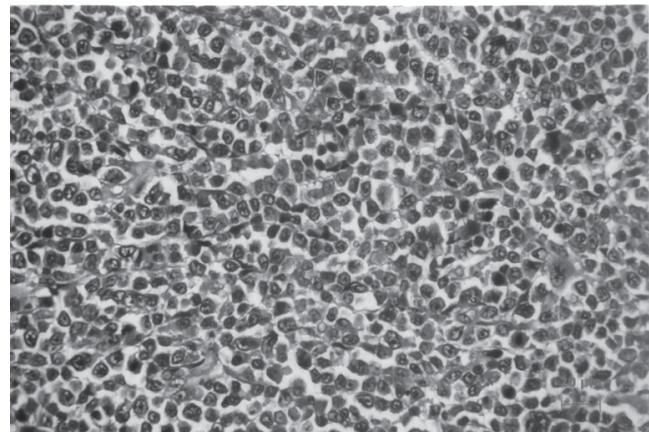

Figura 1 - Linfoma Imunoblástico (Kiel), canino. As células apresentam núcleo redondo com um único nucléolo central. HE os grupos de graus alto e baixo de malignidade.

Entre as neoplasias de grau alto de malignidade (Figura 3), a média de células em proliferação marcadas pelo Ki-67 (MIB-1) foi de 43,19\% $\pm 19,01$, e nos casos de grau baixo de $14,09 \% \pm 11,74$. De acordo com Teste t (student) foi observada diferença estatisticamente significativa

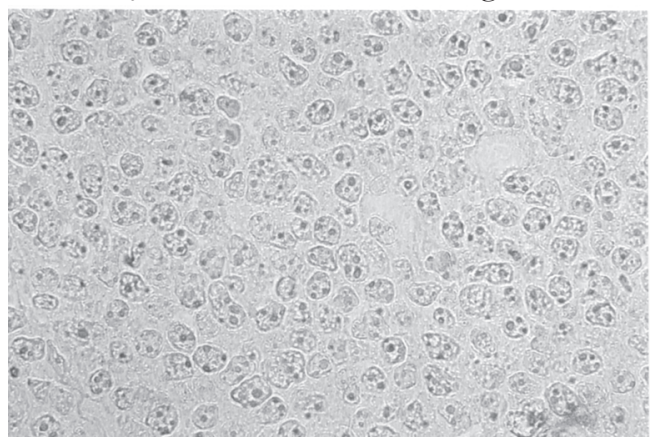

Figura 2 - Linfoma Imunoblástico, canino - múltiplos AgNORs distribuídos pelo núcleo das células neoplásicas e algumas células apresentando um único ponto nuclear (1000x)

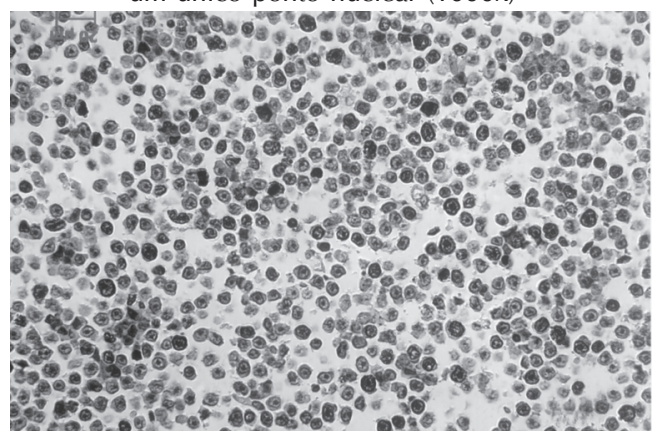

Figura 3 - Linfoma Imunoblástico (Kiel), canino positividade para anticorpo anti- Ki-67 (MIB 1), EnVision, DAB, contracorado com Hematoxilina de Harris 
$(\mathrm{P}<0,01)$ entre os grupos de alto e baixo grau de malignidade.

\section{Discussão}

Os 40 casos de linfoma utilizados neste trabalho foram classificados de acordo com a Classificação de Kiel ${ }^{13}$, onde predominaram os linfomas de grau alto $(72,5 \%)$ em relação aos linfomas de grau baixo $(27,5 \%)$. Este resultado é semelhante ao obtido por autores, que utilizaram esta mesma classificação em material colhido pelo método da Punção Aspirativa por Agulha Fina ${ }^{3,15}$ bem como nos trabalhos que utilizaram esta classificação em exames histológicos $9,16,17,18,19$.

No que diz respeito à determinação do imunofenótipo dos linfomas caninos o emprego dos anticorpos CD3 e CD79a, marcadores de células $T$ e células $B$, respectivamente, tem permitido a utilização de material fixado em formol e incluído em parafina..$^{20,21,22}$ Determinação da origem $T$ ou B dos Linfomas não-Hodgkin tem valor prognóstico e não pode ser definida pela morfologia celular. ${ }^{16,23}$ Os cães portadores de Linfomas $T$ respondem menos ao tratamento quimioterápico e têm tempo de sobrevida menor do que os cães portadores de Linfomas B. ${ }^{23}$ Portanto, a classificação imunocitoquímica dos linfomas torna-se um procedimento importante para a definição do comportamento clínico da neoplasia e sua resposta ao tratamento quimioterápico. ${ }^{2,89,12,18,23}$

$\mathrm{Na}$ casuística utilizada neste trabalho foi observado o mesmo número de casos com imunofenótipo T (CD3+/CD79a-) e imunofenótipo B (CD3-/CD79a+), sendo 17 casos $(42,5 \%)$ de cada imunofenótipo seguido pelos linfomas de imunofenótipo T/B (CD3+/CD79+) em 15\% dos casos, resultados semelhantes aos encontrados em outro estudo, com os mesmos anticorpos. ${ }^{22}$ Em trabalhos realizados anteriormente em nosso laboratório com material incluído em parafina ${ }^{20}$ e em material citológico ${ }^{15}$, detectaram a predominância dos linfomas de imunofenótipo T. Milner et al. ${ }^{18}$ referem o mesmo tipo de achado, utilizando um painel mais amplo de anticorpos. A freqüência encontrada por estes autores foi de $60 \%$ de Linfomas T e $40 \%$ de Linfomas B.

No entanto, a maioria dos autores que trabalhou com imunofenotipagem dos linfomas caninos relata a predominância dos Linfomas B em suas casuísticas, embora também ocorra grande variação nas freqüências encontradas e na metodologia empregada. $2,9,12,18,24$

A freqüência de Linfomas B variou de $55,1 \%$ a $77,7 \%$ nas casuísticas dos autores que verificaram o predomínio deste imunofenótipo utilizando painéis de anticorpos amplos em material citológico ou incluído em parafina. ${ }^{3,9,19,24}$ Deve-se ressaltar que mesmo com o predomínio do imunofenótipo $\mathrm{B}$, a freqüência dos Linfomas T pode ser alta, chegando a $42 \%$ dos casos. ${ }^{3}$

\section{Índice de Proliferação Celular} pelo método do Ki-67 (MIB-1)

Quando analisada a marcação com Ki-67 para proliferação celular, pode-se notar diferença significativa dos índices de proliferação entre os grupos de graus alto e baixo de malignidade e este resultado concorda com a literatura, tanto para linfomas caninos como linfomas nãoHodgkin dos seres humanos. 5,9,25,26,27

Em estudo que analisou 92 casos de linfomas caninos, observou que os linfomas de grau baixo de malignidade possuíam índices de proliferação entre 3 e $16 \%$ e os de grau alto, entre 39 e $60 \% .{ }^{12}$ No mesmo trabalho, os autores relatam que dentre os linfomas de grau baixo, dois casos apresentaram média maior que os $21 \%$, sendo o maior, um linfoma Centrocítico com 30\% de células positivas para o marcador Ki-67. Todos os linfomas de alto grau apresentaram índice proliferativo maior que o limite de $21 \%$, sendo então estabelecido o limite percentual de $21 \%$ entre os tumores de graus alto e de baixo de malignidade.

No presente trabalho, a variação da proliferação entre os linfomas de baixo estava entre 1,67 e $34,5 \%$ e considerando os 
de grau alto, esta variou entre 24,4 e $80,53 \%$. Utilizando o limite de $21 \%$ como parâmetro para dividir as neoplasias de acordo com o grau de malignidade, obteve-se três casos de grau baixo com percentual maior que o limite, sendo o maior um linfoma Centrocítico com $34,5 \%$ de células marcadas e todos os de grau alto apresentaram o índice de proliferação maior que $21 \%$, sendo o menor, com $24,4 \%$ um linfoma Imunoblástico.

Este mesmo parâmetro de percentual de células em proliferação de divisão dos linfomas em graus alto e baixo de malignidade foi estabelecido nos linfomas dos seres humanos em trabalhos com valores de $20 \%$ e $26 \% .^{10,11}$

Os valores observados, na literatura consultada, para os índices proliferativos demonstram que em alguns tipos citológicos podem ocorrer discrepâncias quanto a estes parâmetros e, portanto, o índice de proliferação celular deve ser analisado juntamente com a classificação citohistológica dos linfomas para estabelecer o padrão de comportamento da neoplasia. Os linfomas de alto grau de malignidade, nas espécies humanas e caninas, com um alto índice de proliferação celular tendem a responder melhor a quimioterapia. ${ }^{9,26}$ Assim sendo, os índices proliferativos devem ser considerados, principalmente, na análise de casos individuais da rotina de diagnóstico a fim de auxiliar a escolha do tratamento.

Em nosso estudo, a média de número de AgNORs intranuclear nos linfomas de alto grau de malignidade foi estatisticamente maior que nos linfomas de grau baixo, o que corrobora os dados presentes na literatura consultada. ${ }^{7,28,29}$

Embora o número maior de AgNORs nos linfomas de grau alto de malignidade que nos de baixo grau concorde com vários autores, as médias encontradas no neste estudo foram mais baixas que as médias da literatura consultada. Os linfomas de baixo grau apresentaram uma media de $0,98 \pm 0,36$ e os de alto grau, 1,37 $\pm 0,32$. Estudo utilizando o mesmo tipo de material, encontrou para os linfomas de baixo grau, em média um ponto de AgNOR por núcleo e nas neoplasias de alto grau, foram contados cinco AgNORS por núcleo. ${ }^{14}$ Outro estudo, quando utilizaram material histológico e citológico para contagem dos AgNORs, obtiveram nas amostras histológicas a variação de 2,2 a 3,0 nos linfomas de baixo grau e 2,6 a 3,7 nos de alto grau. ${ }^{29}$ Estes mesmos autores relatam que estas diferenças nas médias de diversos trabalhos podem ocorrer devido a alterações durante o processamento desde a fixação do material, processamento histológico até mesmo durante a coloração pela prata. A técnica utilizada para corar os linfomas deste estudo seguiu o mesmo padrão descrito por diversos autores. No entanto, os tempos de fixação do material, desparafinização e desidratação não foram padronizados nos casos resgatados do arquivo. Estas variações podem interferir na impregnação da prata, formando grandes agregados ao invés de pequenos pontos, isso leva a um excesso de prata intranuclear e reduz o número de pontos contados nos núcleos interferindo na média de AgNORs. ${ }^{29}$

Quando foram comparados os resultados deste trabalho com outro estudo realizado no mesmo laboratório nota-se que mesmo havendo diferenças entre os graus de malignidade, as médias deste trabalho foram maiores que no presente estudo. ${ }^{22}$ Esta diferença pode ser devido ao tipo de material utilizado por $\mathrm{Pessoa}^{22}$, que utilizou amostras colhidas por meio de citologia aspirativa. Segundo Valdovich et al. ${ }^{29}$, mesmo utilizando amostras citológicas e histológicas dos mesmos casos, obtiveram números maiores de AgNORs nos exames citológicos e de acordo com estes autores, as células nas amostras citológicas apresentam-se íntegras e não fatiadas pelo micrótomo como nas preparações histológicas, por isso o número de AgNORs seria maior e os NORs pequenos seriam mais facilmente reconhecidos. Mesmo assim, o método de contagem do AgNORs, é de grande eficácia na determinação do grau de malignidade dos linfomas caninos, tanto nas amostras histológicas como naquelas colhidas pela 
citologia aspirativa.

Quando analisados os linfomas de alto grau, os linfomas Centroblásticos apresentavam a maior média no número de AgNORs, no presente trabalho, os tipos de neoplasia que mostraram as maiores quantidades de pontos intranucleares foram os linfomas Imunoblásticos, seguidos pelos Centroblásticos. ${ }^{14}$

O padrão de distribuição encontrado em todos casos de linfoma nesta pesquisa, corresponde ao tipo II, que apresenta vários aglomerados de NORs no núcleo. Alguns autores verificaram, estudando pacientes com leucemias crônicas, que o prognóstico de leucemia progressiva estava relacionado com um número maior de aglomerados de NORs e as amostras com NORs únicos, os pacientes eram considerados estáveis. $\mathrm{O}$ número de AgNORs nas células malignas é maior que nas hiperplásicas ou benignas e está associado com a alta taxa de proliferação celular. ${ }^{14,29,30,31,32}$ Estes últimos autores obtiveram cerca de $80 \%$ das neoplasias classificadas no padrão de distribuição II e o padrão em todas as amostras de linfonodos normais ou reativos possuem apenas um agregado pequeno.

\section{Agradecimentos}

Apoio financeiro FAPESP: processo $n^{\circ} 04 / 08732-1$.

\section{Cell proliferation in canine lymphoma}

\section{Abstracts}

Lymphoma studies deals with morphological classification and immunophenotypic features and they have to be amplified for cellular kinetics evaluation. This evaluation can only be safely made, when the proliferative index are evaluated. In men the proliferation index have, most of the time, important influence in the neoplasia prognosis and treatment In this work it was used 40 canine lymphomas that were classified according to Kiel methods and immunophenotype was achieved with CD3 (T lymphocyte) and CD79a (B lymphocyte). Cellular proliferation was evaluated by AgNORs and Ki-67 (MIB-1) According to Kiel classification system, high grade lymphomas were more frequent and $\mathrm{T}$ and $\mathrm{B}$ lymphoma showed the same frequency. When cellular proliferation was evaluated, there was a significant difference between high grade and low grade lymphomas by AgNOR and Ki-67 (MIB-1) methods, but did not differ when comparing immunophenotype. Among high grade malignancy lymphomas the NORs medium number per cell nucleoli was $1.37 \pm$ 0.32 and in low grade was $0.98 \pm 0.36$, concerning $\mathrm{Ki}-67$ the positive cellular percentual was $43.19 \% \pm 19.01$, e $14.09 \% \pm 11.74$ in high and low grade, respectively

\section{Referências}

1 CAPURRO, C.; BURACCO, P.; ROSSI, L. Lymphoma in dog. Europ. J. Com. An. Pract., v. 4, p. 15-29, 1992.

2 TESKE, E. et al. Prognostic factors for treatment of malignant lymphoma in dogs. JAVMA, v. 205, n. 12. p. 1722-1728, 1994.

3 TESKE, E.; VAN HEERDE, P. Diagnostic value and reproducibility of fine needle aspiration cytology in canine malignant lynfoma. The Veterinary Quarterly, v. 18, n. 3, p. 112-115, 1996.

4 VONDERHAAR, M. A.; MORRISON, W. B. Lymphosarcoma. In: MORRISON, W. B. Cancer in dogs and cats. Philadelphia: Williams \& Wilkins. 1998. p. 667-695.

5 KIUPEL, M.; TESKE, E.; BOSTOCK, D. Prognostic factors for treated canine malignant lymphoma. Vet. 
Pathol., v. 36, p. 292-300, 1999.

6 ROESL S, S.; TILMANT, R.; DUCATELLE, R. PCNA and $\mathrm{KI}-67$ proliferation markers as criteria for prediction of clinical behaviour of melanicitic tumours in cats and dogs. J. Comp. Pathol., v. 121, p. 13-24, 1999.

7 CROKER, J.; NAR, P. Nucleolar organizer regions in lymphomas. J. Pathol., v. 151, p. 111-118, 1987.

8 ALVES, V. A. F.; BACCHI, C. E.; VASSALO, J. Manual de imuno-histoquímica. São Paulo: Sociedade Brasileira de Patologia, 1999. 270 p.

9 FOURNEL-FLEURY, C. et al. Growth fractions in canine non-Hodgkin's lymphomas as determined in situ by the expression of Ki-67 antigen. J. Comp. Path., v. 117, n. 1, p. 61-72, 1997.

10 GERDES, J. et al. Immunobiochemical and molecular biologic characterization of the cell proliferationassociated nuclear antigen is defined by monoclonal antibody Ki-67. Am. J. Pathol., v. 138, p. 867-873, 1991.

$11 \mathrm{HALL}, \mathrm{P}$. A. et al. The prognostic value of Ki-67 immunostaining in non-Hodgkin's lymphoma. J. Pathol., v. 154, p. 223-235, 1988.

12 FOURNEL-FLEURY, C. et al. Canine T-cell lymphoma: a morphological, immunological, and clinical study of 46 new cases. Vet. Pathol., v. 32, p. 92-109, 2002

13 LENNERT, K.; FELLER, A. C. Histopathology of non-Hodgkin's lymphomas 2. ed. Berlim: Springer, 1990. 312 p.

14 CROCKER, J.; BOLDY, D. A.; EGAN, M. J. How should we count AgNORs? Proposals for a standarzed approach. J. Pathol., v. 158, p. 185-188, 1988.

15 SUZANO, S. M. C. Classificação citológica e imunocitoquímica dos linfomas caninos. 2004. 110 f. Dissertação (Mestrado) - Universidade Estadual Paulista, Botucatu, 2004.

16 APPELBAUM, F. R. et al. Phenotyping of canine lymphoma with monoclonal antibodies directed at cell surface antigens: classification, morphology, clinical presentation and response to chemotherapy. Hematol. Oncol., v. 2, p. 151-168, 1984.

17 GREENLEE, P. G.; FILIPPA, D. A.; QUIMBY, F. W. Lymphoma in dogs: a morphologic, imunologic and clinical study. Cancer, v. 66, p. 480-490, 1990.

18 TESKE, E. Canine malignant lymphoma: A review and comparion whit human non-Hodgkin's lymphoma. Vet. Q., v. 16, n. 4, p. 209-219, 1994.

19 SUEIRO, F. A. R.; ALESSI, A. C.; VASSALO, J. Canine lymphomas: a morphological and immunohistochemical study of 55 cases, with observations on p53 immunoexpression. J. Comp. Pathol., v. 131, p. 207-
213, 2004.

20 DE MOURA, V. M. B. D. Classificação citohistológica e imunofenotipagem dos linfomas caninos. 2000. 107 f. Dissertação (Mestrado) Universidade Estadual Paulista, Botucatu, 2005.

21 MILNER, R. J. et al. Immunophenotypic classification of canine malignant lymphoma on formalin-fixed paraffin wax-embedded tissue by means of CD3 and CD79a cell markers. Onderstepoort J. Vet. Res., v. 63, p. 309-313, 1996.

22 PESSOA, A. W. P. Classificação citohistológica, imunoistoquímica, lesão de DNA, morfometria e índice de proliferação celular nos linfomas caninos. 2005 187 f. Tese (Doutorado) - Universidade Estadual Paulista, Botucatu, 2005.

23 DOBSON, J. M. et al. Prognosyic variables in canine multicentric lymphossarcoma. J. Small Anim. Pract., v. 42, p. 377-384, 2001.

24 CANIATTI, M. et al. Canine Iymphoma: immunocytochemical analysis of fine needle aspiration biopsy. Vet. Pathol., v. 33, p. 204-212, 1996.

25 MADEWELL, B. R. Cellular proliferation in tumors: a review of methods, interpretation, and clinical applications. J. Vet. Intern. Med., v. 15, p. 334-340, 2001.

26 PHILLIPS, B. S. et al. Apoptotic and proliferation indexes in canine lymphoma. J. Vet. Diagn. Invest., $v$. 12, n. 2, p. 111-117, 2000.

27 WANG, S. A. et al. Low histologic grade follicular lymphoma with high proliferation index: morphologic and clinical features. Am. J. Surg. Pathol., v. 29, p. 1490 -1496, 2005

28 VAIL D. M. et al. Assessment of potencial doubling time $\left(\mathrm{T}_{\mathrm{oo}}\right)$, argyrophilic nucleolar organizer regions (AgNOR), and proliferating cell nuclear antigen (PCNA) as predictors of thepapy response in canine nonHodgkin's lymphoma. Exp. Haematol., v. 24, p. 807815, 1996.

$29 \mathrm{VALDOVICH}, \mathrm{P}$. et al. Use of the nucleolar region method for cytologic and histologic examination of the lymph nodes in dogs. Vet. Pathol., v. 41, p. 338-345, 2004.

30 TRERÈ, D. AgNORs staining and quantification. Micron., v. 31, p. 127-131, 2000

31 DERENZINI, M.; PLOTON, D. Interphase nucleolar organizer regions in cancer cells. Review Intern. Exp. Pathol., v. 32, p. 149-192, 1991.

32 RABENHORST, S. H.; BURINI, R. C.; SCHIMITT, F. C. L. Ciclo celular: mecanismos reguladores e marcadores bioquímicos. Res. Brás. Cancerol., v. 40, p. 3, p. 141-147, 1994. 